\title{
A Short Glossary of Inclusive Language
}

\author{
Compiled by Susanne E. Craig and EeShan Bhatt
}

Words matter - that old adage that many of us may have heard as children,

\author{
Sticks and stones may break my bones, \\ but words will never hurt me,
}

is a harmful fallacy. In reality, the language we use has tremendous power to alienate, exclude, deride, humiliate, and wound.

On the other hand, thoughtful use of language can signal openness, inclusivity, admiration, and celebration, or simply be an expression of empathy and care for our fellow humans. As part of The Oceanography Society (TOS) Justice, Equity, Diversity, and Inclusion Committee's series of columns in Oceanography, here we provide a glossary of terms that are often used while discussing topics such as race, ethnicity, gender, sexual orientation, and gender identity.

It should be explicitly stated that this list is neither definitive nor exhaustive. Indeed, the terms included here are likely heavily influenced by the authors' own lived experiences and the lenses through which we see the world. Language is a living entity, a fluid social construct subject to rapid changes and overlaid with regional nuances. Indeed, what may be accurate and acceptable terminology for one person may be entirely unacceptable for another. Keeping this in mind, the following glossary is an attempt to group together some of the acronyms and phrases that are most commonly used today in social justice studies and bodies of work and that may have particular relevance to our

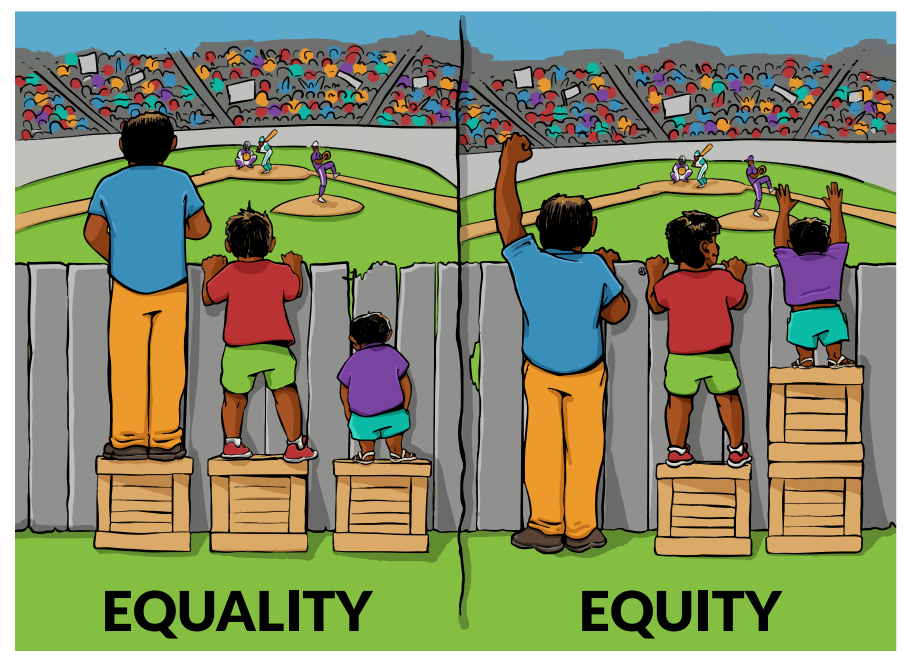

FIGURE 1. The difference between equality and equity. Interaction Institute for Social Change, Illustration by Angus Maguire, https://interactioninstitute.org/illustrating-equality-vs-equity/ community of ocean-related scientists, technologists, and stakeholders. We have borrowed heavily from a wide range of excellent existing scholarship and activism and have cited all sources used. We encourage the reader to follow the links to these multimedia resources and, perhaps, use them as teaching and discussion materials with your students, colleagues, and mentees. Finally, it is our hope that this glossary, along with the links provided to more comprehensive definitions and discussions, helps to define terms that you may have heard used, but not understood, and that it will serve to remind us of the power of the words we use in our everyday professional and personal lives.

We begin by defining the very words that form the name of our committee: Justice, Equity, Diversity, and Inclusion (JEDI).

\section{JUSTICE}

Justice is fairness in the way that people are treated. ${ }^{1}$ However, in the context we discuss it here, it is more correct to define social justice. This term can be formally defined in several ways $^{2}$ and references therein , but the overarching principles common to all definitions are:
- Equal rights
- Equal opportunity
- Equal treatment

Or, in other words, social justice means equal rights and equitable opportunities for all. ${ }^{2}$

When we think of implementing social justice in our communities, some examples might include correcting the racial, gender-based, socioeconomic, or geographical injustices and inequities that have created barriers to those entering our field, bringing to bear our professional capabilities in the field of environmental justice (see Table 1 for a definition of this term, which is strongly related to social justice), and/or confronting our relationship with colonial science (see Table 1 for a definition of decolonizing science).

\section{EQUITY}

Equity refers to fairness and justice and is distinguished from equality in that, whereas equality means providing the same to all, equity means recognizing that we do not all start from the same place and must acknowledge and make adjustments to counter imbalances (Figure 1). This is an ongoing process that requires us to identify and overcome intentional and unintentional barriers arising from bias or systemic structures. ${ }^{3}$ 
TABLE 1. A glossary of terms.

AAPI The many diverse groups of people with Asian, Asian American, or Pacific Islander ancestry.

In the social justice sense, allies are those who make the commitment and effort to recognize their privilege (based on gender,

Ally class, race, sexual identity, etc.) and work in solidarity with oppressed groups in the struggle for justice. Allies understand that it is in their own interest to end all forms of oppression, even those from which they may benefit in concrete ways. ${ }^{4}$

Bias is a prejudice in favor of or against one thing, person, or group compared with another, usually in a way that is considered to be unfair. Biases may be held by an individual, a group, or an institution and can have negative or positive consequences.

There are types of biases:

- Conscious bias (also known as explicit bias), and

- Unconscious bias (also known as implicit bias).

It is important to note that biases, conscious or unconscious, are not limited to ethnicity and race. Though racial bias and discrimination are well documented, biases may exist toward any social group. One's age, gender, gender identity, physical abilities, religion, sexual orientation, weight, and many other characteristics are subject to bias.

Unconscious biases are social stereotypes about certain groups of people that individuals form outside their own conscious awareness. Everyone holds unconscious beliefs about various social and identity groups, and these biases stem from our tendency to organize social worlds by categorizing.

Unconscious bias is far more prevalent than conscious prejudice and is often incompatible with conscious values. Certain scenarios can activate unconscious attitudes and beliefs. For example, biases may be more prevalent when multitasking or working under time pressure. ${ }^{6}$

BIPOC

Black, Indigenous, and People of Color. Mostly used in North America. See references ${ }^{7-10}$ for discussions on the origins of this term and its use.

BAME Black, Asian, and Minority Ethnic. Used in the UK, but see references ${ }^{11-13}$ for recent discussions on the acceptability of its use. Black Lives Matter: A political movement to address systemic and state violence against African Americans. ${ }^{4}$ Per the Black Lives Matter organizers: "In 2013, three radical Black organizers-Alicia Garza, Patrisse Cullors, and Opal Tometi-created a Blackcentered political will and movement building project called \#BlackLivesMatter. It was in response to the acquittal of Trayvon

BLM Martin's murderer, George Zimmerman. The project is now a member-led global network of more than 40 chapters. [Black Lives Matter] members organize and build local power to intervene in violence inflicted on Black communities by the state and vigilantes. Black Lives Matter is an ideological and political intervention in a world where Black lives are systematically and intentionally targeted for demise. It is an affirmation of Black folks' humanity, our contributions to this society, and our resilience in the face of deadly oppression."14

Decolonizing

Science

Decolonization is a movement to eliminate, or at least mitigate, the disproportionate legacy of White European thought and culture in education ${ }^{15}$ [and science]. For further discussion and examples of the decolonialization of science, see references ${ }^{16-18}$ and references therein.
First coined by American sociologist Arlie Hochschild in her 1983 book The Managed Heart: Commercialization of Human Feeling ${ }^{19}$, emotional labor means to: "induce or suppress feeling in order to sustain the outward countenance that produces the proper state of mind in others." Emotional labor involves the management of personal feelings and behaviors to align with institutional (or other organizational or individual) expectations, even when dealing with emotionally charged situations. It's an often

Emotional

Labor text of race dialogues, either in the workplace or in more individual settings (e.g., with friends, family, or on social media), this can translate into minorities' sharing some of their most painful experiences for the collective good, while being careful to manage their emotions so as not to make things awkward for others after the conversation. ${ }^{20}$

"See reference ${ }^{21}$ on use of the word "minority"

Any policy, practice, or directive that differentially affects or disadvantages (whether intended or unintended) individuals, groups, or communities based on race. This term refers to how minority group neighborhoods, which are populated primarily by people of color and those from low socioeconomic backgrounds, are burdened with disproportionate numbers of hazards, including toxic waste facilities, garbage dumps, and other sources of environmental pollution and foul odors that lower the quality of life.

Environmental

Racism Examples of environmental racism include:

- The devastating pollution of the Boat Harbour water body (and surrounding airshed) in Nova Scotia, Canada-an ancestral fishing ground of the Mi'kmaq First Nation-by the discharging of effluent from a pulp mill 22 and extensive studies cited therein , and

- "Cancer Alley" in Louisiana, USA-a corridor of petrochemical plants that has polluted the surrounding water and air and subjected the mostly African American residents in St. James Parish to cancer, respiratory diseases, and other health problems. ${ }^{23}$

The fair treatment and meaningful involvement of all people regardless of race, color, national origin, or income with respect to

Environmental the development, implementation, and enforcement of environmental laws, regulations, and policies. ${ }^{24}$ The environmental jusJustice tice movement grew out of a need to respond to environmental racism, and each global region has its own unique history of environmental justice development. ${ }^{25-29}$

A social construct that divides people into smaller social groups based on characteristics such as shared sense of group Ethnicity membership, values, behavioral patterns, language, political and economic interests, history, and ancestral geographical base. ${ }^{4}$ and references therein 
Gaslighting is a form of psychological abuse where a person or group makes someone question their sanity, perception of reality, or memories. Examples of gaslighting in social justice terms include "racial gaslighting," which is a way of maintaining a pro-

Gaslighting White/anti-Black balance in society by labeling those who challenge acts of racism as psychologically abnormal ${ }^{30}$ and minimizing or dismissing people's real and legitimate trauma through statements such as "Women in other countries have it much worse!" or "Don't be the PC police!" 31

Generational

Trauma

(also known as intergenerational

or transgenera-

tional trauma)

Trauma that isn't experienced just by one person but extends from one generation to the next. It is thought that the effects of the trauma can be passed from generation to generation in a number of ways that include learned beliefs, behaviors, and patterns, and genetic processes. ${ }^{32}$ Examples of populations affected by generational trauma include African Americans who are subjected to pervasive systemic racism, families of US indigenous and Canadian First Nations children forced into residential school systems, and families of Holocaust survivors. ${ }^{33}$ and references therein

A gender-neutral English neologism, sometimes used to refer to people of Latin American cultural or ethnic identity in the United

Latinx States. The "x" suffix replaces the "o"/ $a$ " ending of Latino and Latina that are typical of grammatical gender in Spanish. Its plural is Latinxs. Words used for similar purposes include Latin@, Latine, and Latinidad. ${ }^{34}$

LGBTQI+

Lesbian, Gay, Bisexual, Transgender, Queer, Intersex. The + indicates that there are identities beyond the six listed here that include, but are not limited to, Two Spirited, pansexual, omnisexual, asexual, and allies of these identity groups. ${ }^{35}$

The everyday verbal, nonverbal, and environmental slights, snubs, or insults, whether intentional or unintentional, that

Microaggression communicate hostile, derogatory, or negative messages to target persons based solely upon their marginalized group membership. 4 and sources therein

The systematic subjugation of one social group by a more powerful social group for the social, economic, and political benefit of the more powerful social group.

Oppression exists when the following four conditions are met: ${ }^{36}$

- The oppressor group has the power to define reality for themselves and others

- The target groups take in and internalize the negative messages about them and end up cooperating with the oppressors (thinking and acting like them)

- Genocide, harassment, and discrimination are systematic and institutionalized, so that individuals are not necessary to perpetuate it

- Members of both the oppressor and target groups are socialized to play their roles as normal and correct

Oppression $=$ Power + Prejudice ${ }^{37}$

Performative

Allyship

POC

Performative allyship is when someone from a non-marginalized group professes support and solidarity with a marginalized group in a way that either isn't helpful or that actively harms that group. Performative allyship usually involves the "ally" receiving some kind of reward, for example, on social media-that virtual pat on the back for being a "good person" or "on the right side." 38

Person(s) of Color. While this term is affirming (in a way that non-White is not), there is significant variation of experiences among POC. In conversation, it is best practice to be as specific as possible and reciprocate the language any POC may use to describe themselves.

Systems and structures that have procedures or processes that create disadvantages for people of color. It is the complex interaction of culture, policy, and institutions that holds in place the outcomes people of color see in their lives. Systemic racism is, essentially, naming the process of White supremacy. It creates disparities in many "success indicators," including wealth, the criminal justice system, employment, housing, health care, politics, and education. The concept dates back to work done by scholar and civil rights pioneer W.E.B. Du Bois ${ }^{39}$ and was first named during the civil rights movement of the 1960 s and was further refined in the $1980 \mathrm{~s}^{40}$

Systemic

Racism

(also known

as structural or

institutional

racism)

Examples of how this type of racism manifests include:

- In the United States, glaring disparities between rates of arrest and incarceration for the BIPOC communities and White people $\mathrm{e}^{41}$

- Huge life expectancy disparities between Aboriginal and non-Aboriginal Australians ( $\leq 21$ years for men and $\leq 19$ years for women) thought to be strongly related to the inferior healthcare that Aboriginal peoples receive in the healthcare system as well as other systemic inequities ${ }^{42}$

- In the United States, government policies that explicitly restrict the ability of people to get loans to buy or improve their homes in neighborhoods with high concentrations of African Americans (also known as "redlining") 4

- In the UK universities system, the finding that people of color comprise a tiny proportion of professor positions, with just 17 Black women in those positions in 2015 and ethnic minority groups earning on average $26 \%$ less than their White colleagues ${ }^{43}$

White

Centering

White

Fragility

White

Privilege
White centering is the centering of White people, White values, White norms, and White feelings over everything and everyone else..$^{44}$

A state in which even a minimum amount of racial stress becomes intolerable [for White people], triggering a range of defensive responses. These responses include the outward display of emotions such as anger, fear, and guilt, and behaviors such as argumentation, silence, and leaving the stress-inducing situation. These behaviors, in turn, function to reinstate White racial equilibrium. ${ }^{4}$ and references therein

Refers to the unquestioned and unearned set of advantages, entitlements, benefits, and choices bestowed on people solely because they are White. Generally, White people who experience such privilege do so without being conscious of it. ${ }^{4}$ 


\section{DIVERSITY}

Diversity is expressed in various forms, including race and ethnicity, gender and gender identity, sexual orientation, socioeconomic status, language, culture, national origin, religious commitments, age, disability status, ideas, perspectives, and values. Efforts to achieve diversity in a community are valuable, but they do not constitute a strategy to address inequity and injustice, and are criticized by many. ${ }^{45}$ For example, the US-based Baltimore Racial Justice Action states: "Diversity is silent on the subject of equity. In an anti-oppression context, therefore, the issue is not diversity, but rather equity. Often when people talk about diversity, they are thinking only of the "non-dominant" groups." 4 and references therein

In our oceanographic community, efforts to realize true diversity are sorely wanting, and acquiring and understanding data on diversity metrics is in its infancy. We must engage with our social science colleagues if we are to form a holistic understanding of the lack of diversity in oceanography and develop effective strategies to address it.

\section{INCLUSION}

Inclusion is the action or state of including or of being included within a group or structure. More than simply diversity and numerical representation, inclusion involves authentic and empowered participation and a true sense of belonging. ${ }^{5}$ 巴

\section{REFERENCES AND FURTHER READING}

1. Justice Definition and Meaning | Collins English Dictionary, https://www.collinsdictionary.com/us/dictionary/english/justice.

2. The San Diego Foundation. 2016. "What is Social Justice?" March 24, 2016, https://www.sdfoundation.org/news-events/sdf-news/what-is-social-justice/.

3. Equity Definition, https://www.naceweb.org/about-us/equity-definition/.

4. Glossary / Racial Equity Tools, https://www.racialequitytools.org/glossary.

5. The Annie E. Casey Foundation. 2021. "Equity vs. Equality and Other Racial Justice Definitions," updated April 21, 2021, https://www.aecf.org/blog/ racial-justice-definitions.

6. University of California, San Francisco. N.D. "Unconscious Bias," https://diversity.ucsfedu/resources/unconscious-bias.

7. Grady, C. 2020. "Why the Term 'BIPOC' is so Complicated, Explained by Linguists." Vox, June 30, 2020, https://www.vox.com/2020/6/30/21300294 bipoc-what-does-it-mean-critical-race-linguistics-jonathan-rosa-deandra-mileshercules.

8. Cherry, K. 2020. "What Does the Acronym BIPOC Mean?" VeryWellMind, updated September 17, 2020, https://www.verywellmind.com/ what-is-bipoc-5025158.

9. The BIPOC Project, https://www.thebipocproject.org/.

10. Grisby, L. 2021. "What Does BIPOC Stand For? Why It's Important to Know What This Acronym Means." Reader's Digest, updated May 28, 2021 https://www.rd.com/article/what-does-bipoc-stand-for/.

11. Mistlin, A. 2021. "So the Term BAME Has Had Its Day. But What Should Replace It?” The Guardian, April 8, 2021, https://www.theguardian.com commentisfree/2021/apr/08/bame-britain-ethnic-minorities-acronym.

12. Bunglawala, Z. 2019. "Please, Don't Call Me BAME or BME!" UK Civil Service Blog, July 8, 2019, https://civilservice.blog.gov.uk/2019/07/08/ please-dont-call-me-bame-or-bme/.

13. The Law Society. 2020. "A Guide to Race and Ethnicity Terminology and Language." December 7, 2020, https://www.lawsociety.org.uk/en/topics/ethnic minority-lawyers/a-guide-to-race-and-ethnicity-terminology-and-language.

14. Black Lives Matter. "Herstory," https://tinyurl.com/2yhhyp7z.

15. Nordling, L. 2018. How decolonization could reshape South African science. Nature 554:159-162, https://doi.org/10.1038/d41586-018-01696-w.

16. Prescod-Weinstein, C. 2015. "Decolonising Science Reading List." April 25, 2015, https://medium.com/@chanda/decolonising-sciencereading-list-339fb773d51f.
17. Roy, R.D. 2018. "Decolonise Science-Time to End Another Imperial Era." The Conversation, April 5, 2018, https://theconversation.com/ decolonise-science-time-to-end-another-imperial-era-89189.

18. Decolonization of Knowledge - Wikipedia, https://en.wikipedia.org/wiki/ Decolonization_of_knowledge.

19. Hochschild, A.R. 2012. The Managed Heart: Commercialization of Human Feeling. University of California Press, $352 \mathrm{pp}$.

20. Tiayon, S.B. 2020. "How to Avoid Doing Harm When You Discuss Race at Work." Greater Good Magazine, September 14, 2020, https://greatergood. berkeley.edu/article/item/how_to_avoid_doing_harm_when_you_discuss_ race_at_work.

21. The Associated Press. 2005. "What to Call a 'Minority' Group that Isn't?" NBC News, August 18, 2005, https://www.nbcnews.com/id/wbna9001157.

22. Boat Harbour, Nova Scotia - Wikipedia, https://en.wikipedia.org/wiki/ Boat_Harbour,_Nova_Scotia.

23. "Environmental Racism in Louisiana's 'Cancer Alley' Must End, say UN Human Rights Experts." UN News, March 2, 2021, https://news.un.org/en/ story/2021/03/1086172.

24. US EPA. “Learn About Environmental Justice," https://www.epa.gov/ environmentaljustice/learn-about-environmental-justice.

25. "Dr. Robert Bullard-Father of Enviromental Justice," https://drrobertbullard.com/.

26. US EPA. “Environmental Justice Timeline," https://www.epa.gov/ environmentaljustice/environmental-justice-timeline.

27. Carruthers, D.V., ed. 2008. Environmental Justice in Latin America. The MIT Press, $344 \mathrm{pp}$.

28. Grassroots International. "Climate Justice," https://grassrootsonline.org/ what-we-do/the-issues/climate-justice/.

29. Climate Justice Aotearoa, http://www.climatejusticeaotearoa.org/.

30. Wolstenholme, R. 2020. "The Hidden Victims of Gaslighting." BBC Future, November 24, 2020, https://www.bbc.com/future/ article/20201123-what-is-racial-gaslighting.

31. Meldrum, L. 2021. "Gaslighting: The Silencing Weapon." UNH Today, February 5, 2021, https://www.unh.edu/unhtoday/2021/02/gaslightingsilencing-weapon.

32. Gillespie, C. 2020. "What Is Generational Trauma? Here's How Experts Explain It." Health, October 27, 2020, https://www.health.com/condition/ptsd/ generational-trauma.

33. DeAngelis, T. 2019. The legacy of trauma. Monitor on Psychology 50(2):36, https://www.apa.org/monitor/2019/02/legacy-trauma.

34. Latinx - Wikipedia, https://en.wikipedia.org/wiki/Latinx.

35. "The Missing Letters: Beyond LGBTQI+." The Athenaeum, November 19, 2015, http://theath.ca/opinions/the-missing-letters-beyond-lgbtqi/.

36. Hardiman, R., B. Jackson, and P. Griffin. 2007. Conceptual foundations for social justice education. Pp. 35-66 in Teaching for Diversity and Social Justice, 2nd ed., Routledge/Taylor \& Francis Group.

37. dRworksbook. "Racism Defined," https://www.dismantlingracism.org/racismdefined.html.

38. Phillips, H. 2020. "Performative Allyship Is Deadly (And What to Do Instead)." Forge, May 9, 2020, https://forge.medium.com/performative-allyship-is-deadlyc900645d9f1f.

39. NAACP. "W.E.B. Du Bois," https://naacp.org/find-resources/history-explained/ civil-rights-leaders/web-du-bois.

40. Yancey-Bragg, N. 2020. "Systemic Racism: What Does it Mean and How You Can Help Dismantle It.” USA Today, June 15, 2020 https://www.usatoday.com/story/news/nation/2020/06/15/systemic racism-what-does-mean/5343549002/.

41. Race Forward. "What is Systemic Racism?" Eight-part video series, https://www.raceforward.org/videos/systemic-racism.

42. Henry, B.R., S. Houston, and G.H. Mooney. 2004. Institutional racism in Australian healthcare: A plea for decency. Medical Journal of Australia 180:517-520, https://doi.org/10.5694/j.1326-5377.2004.tb06056.x.

43. Sian, K. 2019. "Extent of Institutional Racism in British Universities Revealed Through Hidden Stories." The Conversation, June 27, 2019 https://theconversation.com/extent-of-institutional-racism-in-british-universities revealed-through-hidden-stories-118097.

44. Saad, L.F. 2020. Me and White Supremacy: Combat Racism, Change the World, and Become a Good Ancestor. Sourcebooks, 256 pp.

45. Stewart, D.-L. 2017. "Language of Appeasement." Inside Higher Ed, March 30, 2017, https://www.insidehighered.com/views/2017/03/30/ colleges-need-language-shift-not-one-you-think-essay.

\section{AUTHORS}

Susanne E. Craig (susanne.e.craig@nasa.gov) is Senior Scientist, NASA GSFC Ocean Ecology Laboratory/Universities Space Research Association, NASA Goddard Space Flight Center, Greenbelt, MD, USA. EeShan Bhatt (ebhatt@ whoi.edu) is Postdoctoral Investigator, Woods Hole Oceanographic Institution, Woods Hole, MA, USA. 